\title{
Community-based quality of life indicators for urban areas as derived in Galway City, Ireland
}

\author{
F. Fahy \& M. Ó Cinnéide \\ Department of Geography, National University of Ireland, \\ Galway, Ireland
}

\begin{abstract}
Promoting quality of life and well-being of citizens is increasingly recognised as an essential component of sustainable urban development. The use of indicators is considered by many to be a key element in giving practical effect to the concept of sustainable cities. However, an emerging body of literature acknowledges that indicators are unlikely to be acceptable or particularly useful unless they are developed in close consultation with their target populations. Community-derived indicators allow individual citizens and communities to express and measure the most important determinants of quality of life for them. This participatory approach raises awareness of elements of the urban environment that are highly valued by citizens and has the potential to contribute to improving local governance. The derivation of quality of life indicators and their observation in urban settings, together with the compilation, analysis, and interpretation of related databases, are highly problematic, not least because the indicators tend to be qualitative in nature and difficult to measure objectively. The use of community-derived quality of life indicators in sustainable urban planning is reviewed in this paper. The process of developing such indicators in Galway (Ireland), one of the fastest growing cities in the EU (as part of a project sponsored by the Irish Environmental Protection Agency), is examined in detail. The manner in which the municipal authority may utilise these indicators to monitor quality of life trends and as a practical tool for bolstering participatory democracy is discussed. This enhanced governance is demonstrated to be a potentially influential process of promoting sustainability practices in cities.
\end{abstract}

Keywords: quality of life indicators, sustainable urban communities, participatory democracy and governance, Ireland. 


\section{Introduction}

Academics and policy-makers formulating sustainable cities initiatives are increasingly concerned with liveability and quality of life issues [1]. Indeed, there is an emerging body of research investigating the measurement of quality of life in urban areas. The use of indicators is considered by many to be a central element in giving practical effect to the concept of sustainable cities [2] and the process of developing such indicators in Galway (Ireland) (as part of a project sponsored by the Irish Environmental Protection Agency), is reported in this paper. This research project is unique in the context of Ireland but draws upon international examples of related research on quality of life and sustainable cities. The study area, namely Galway City, and the city's progress with regard to sustainability and Local Agenda 21 (LA21) is examined initially. The international literature associated with the use of sustainability indicators and with quality of life indicators is then reviewed. In particular an emerging body of research highlighting the importance of community/citizen involvement in indicator development is reviewed. Difficulties involved in measuring aspects of quality of life, which are generally qualitative in nature, are identified. The methodology undertaken to develop community-based quality of life indicators for Galway is outlined in the third section. Preliminary results are presented in the penultimate section of this paper and the manner in which the municipal authority may utilise the research design that has been developed and associated results as a practical tool for measuring quality of life of the citizens of the city and for bolstering participatory democracy, are explored. The potential to influence the process of promoting sustainability practices in cities is considered in the final section.

\section{Galway: a sustainable city?}

Galway is situated on the west coast of Ireland. It is one if the fastest growing urban centres in the EU and had a population of 66,000 people in 2002 [3]. The municipal authority, Galway City Council, has been involved in a local process of sustainable development since the establishment of the Galway City Development Board (CBD) in 2000. In the preparation of the CBD's Strategy for Economic, Social and Cultural Development 2002-2012 a Galway City Atlas was produced and a range of indicators were developed to monitor and promote progress towards specific economic, social and cultural goals. For example three indicators were developed to measure progress towards the CBD's objective of "a safe and healthy city". These indicators are a) number of crimes per annum, b) waiting time for medical and surgical services, and c) membership of sports clubs. However, the indicators that are cited in the strategy are based on quantitative data, that are readily available to the municipal authority and do not include the more general liveability and quality of life issues associated with urban areas.

In July 2005, as part of the research project upon which this paper is based, Galway City Council undertook an evaluation on their progress towards 
sustainable development. The evaluation, entitled Local Evaluation 21, is available to all local authorities in Europe. It was created as a follow-up to the research project LASALA [4] (Local Authorities' Self Assessment of Local Agenda 21), which was funded by the European Commission, DG Research (for more detailed information see www.localevaluation21.org). Although the comparative element of this evaluation is limited, (in that few additional local authorities of similar population size to Galway have undertaken the exercise), the evaluation indicated some of Galway City Councils' strengths and weaknesses with regard to the LA21 and identified opportunities to progress the LA21 process through the local authority. In particular, the evaluation identified several areas within the City Council's LA21 process requiring improvement. For example, a detailed assessment of local priority concerns is currently lacking in Galway City Council's local process for sustainable development. In addition there are currently no mechanisms in place to feed back results of the local process for sustainable development to stakeholder groups or the general public. Specific recommendations to improve the City Council's local process for sustainable development, outlined in the evaluation, include i) the introduction of an evaluation scheme to examine the long term effects of the local sustainability process ii) a need to include targets and measures in order to successfully steer progress towards local sustainable development and iii) increased participation across sectors in order to integrate different perspectives into Galway City Council's local process for sustainable development. Indeed, these recommendations have also been observed at the national scale in Ireland; in the context of Irish sustainability policy two priority areas have been identified, namely, developing practical tools for sustainability assessment and improving public participation in sustainability processes.

The need to develop more effective tools to both promote and assess the process and practices of sustainability has been identified by the EPA as a priority for Irish environmental policy. At national level, the EPA has produced Key Environmental Indicators for Ireland [5]. At local government level, little research has been conducted on sustainability indicators and related sustainability assessment tools. In addition, developing greater public participation in decisions about local places is problematic. In the Irish context, consultation exercises are quite limited and consultation and consensus building exercises on environment and development tend to relate to existing models of environmental policy rather than LA21 per se [6]. Commentators such as Mullally [6] note that one of the most discernible obstacles to measuring LA21 in Ireland is the lack of a systematic approach to increasing community participation.

It is within this context that the current research project is formulated. Key issues arising from the recommendations outlined above, represent major research foci. The primary aim of the research is to develop a set of community derived quality of life indicators for the city of Galway. This participatory approach is utilised not just as a method to raise awareness of elements of the urban environment that are highly valued by citizens but also as a practical tool for bolstering public participation in policy-making and improving the levels of 
trust between local communities and the local authority - in effect shaping sustainability practices through enhanced governance. The development and deployment of sustainability indicators as essential tools for planning and assessing sustainable cities are now examined.

\section{Measuring sustainability in urban areas}

Chapter 40 of the Agenda 21 document calls for the development of indicators for sustainable development [7]. Since then, indicators have become one of the key tools for assessing sustainability [2, 8, 9]. A sustainability indicator "captures and measures a particular aspect of sustainability policy in an easily communicable form, allowing monitoring and subsequent 'steering' of policy, whether by internal management or external political pressure" [10]. A review of the large body of literature on sustainability indicators reveals that many benefits may be achieved through the use of this tool. By measuring specific phenomena in a community e.g. crime rates, recycling rates, car ownership, green land acreage, indicators provide vital information about trends in key environmental values and assist in tracking progress towards stated goals. Indicators are also a method of engaging the community in working towards shared aims and objectives. In addition, researchers such as Gahin et al. [8] perceive indicators as a means of generating community consensus. There are many ways in which indicators can be used including as i) a planning tool, ii) a learning tool iii) a communication tool and iv) a collaborative tool [11].

The process of developing indicators is often viewed as a participatory process that fosters community ownership, builds group credibility, and educates participants. Indicators are unlikely to be as acceptable and used as effectively if they have not been developed in consultation with their target audiences and users [10]. However, the extent to which full engagement and dialogue with citizens occurs is contested. Research conducted by McAlpine and Birnie [12] on the development of indicators for the Island of Guernsey reveals that although best practice literature advises that communities should be involved prior to the development of the indicators, this is not always possible. For example, local communities are not always willing and ready to contribute to the development of sustainability indicators [12].

Over 25 large cities in the United States have developed indicators to track progress towards sustainable development including Portland, San Francisco, and San Jose [9]. The popularity of sustainability indicators within Europe is almost inescapable [12]. For example, the European Commission launched a comprehensive benchmarking in 2003 entitled European Common Indicators: Towards a Local Sustainability Profile. Sommer [13] discusses how indicators are being used in initiatives by local authorities with local groups and communities at the neighbourhood level, to raise awareness of sustainable development and to encourage behavioural change. As they provide information, indicators can 'inspire action' and lead to better decision making. They are regarded as educational tools that can be utilized to raise awareness. Hence, they are viewed as a tool to empower both citizens and decision-makers. However, 
some indicators are easier to identify and maintain than others [9]. Several relevant indicators are collected on a regular basis by government agencies and local authorities e.g. housing, welfare and crime figures. Although attention was focused initially on the relatively technical task of the development and design of indicators, more recently, questions are being raised about the effectiveness of indicators [2]. It appears that there is a dearth of research examining the outcomes of indicator use.

Overall it appears that it is difficult to "discern clear links between the development of an indicator programme and actual changes in decision-making and policy outcomes" [10]. Hence the sustainability indicator research agenda has shifted from design and development towards investigating the links between indicator development and policy action. This new research agenda also highlights the necessity to understand the local context in which the indicators are being developed (this is a marked shift away from the technical approach). A bottom-up approach (where a wide variety of actors are involved) is advocated as opposed to a top-down approach (where local authorities themselves devise and use indicators). Similarly, from this new research perspective, the relations between lay person and expert become very important [10]. Indicators need to be socially constructed as discussed in Journel et al. [14]. Consequently, enabling communities to identify the important issues is vital and this is a fundamental tenet of the research project for which this paper relates.

\section{Quality of life indicators}

Quality of life considerations have only recently emerged in the literature on indicators. Bell and Morse [2] highlight that sustainability is primarily about people and therefore there may be "little point achieving a sustainable system that reduces the quality of life of the people in that system". However, the inclusion of such indicators gives rise to the difficult questions relating to what should be incorporated as quality of life. As noted above, some indicators are easier to identify and maintain than others. Many indicators of quality of life are qualitative in nature and according to Wheeler [9] may be more difficult to measure. One reason for this is that there are a large number of diverse definitions for quality of life. For example, Cutter [15] defines it as "an individual's happiness or satisfaction with life and environment including needs and desires and other tangible and intangible factors which determine overall well being". For Kline [16] quality of life, at a minimum, needs to measure the ability of citizens to get adequate health care, housing, child care, public safety and education. Increasingly, quality of life is being broadly accepted as an essential element of sustainability; however, there is not much consensus on what exactly it is or how it should be included [2]. As a result only limited research has been conducted on quality of life indicators though Wheeler's [9] review of quality of life indicators by the local government in Jacksonville, Florida in 1986 and a more recent project is the Pierce County Quality of Life Benchmark Project, as reported by Devuyst [17], are noteworthy in this respect. At the local level in the UK Bristol City Council has very successfully developed 
quality of life indicators for the city in recent years. Local Agenda 21 Strategy for Bristol provides "a frame-work and set of principles by which the city can move into a more sustainable future" (www.bristol-city.gov.uk).

\section{Research methodology}

The traditional approach to developing quality of life indicators is to conduct quantitative surveys where people are asked for their subjective ratings [9]. However, as Kline [16] notes, quality of life concerns are a reflection of people's beliefs, perceptions and opinions and, as such, indicators need to be developed that can be measured through interviews, focus groups and other qualitative methods. This section discusses the quantitative and qualitative methodologies employed in developing quality of life indicators for the city of Galway.

A major criticism levelled at quality of life projects is that they typically reflect expert opinion about what constitutes quality of life i.e. traditionally these projects do not incorporate how citizens perceive the communities and cities in which they live [18]. Hence, the current research project is situated in the contemporary movement of critical social science which aims to examine issues of quality of life and sustainability from the perspective of the community - the "non-expert voices" [19]. Primary emphasis is on developing a communityderived set of quality of life indicators for Galway which enable individuals to express what is important to them in their city and to allow citizens and policymakers to make decisions based on the results obtained. In addition, the project strives for the involvement of traditionally underrepresented groups, for example, youth. To fulfil these aims both qualitative and quantitative research methods were utilised. Indeed, there are a variety of studies which advocate the combination of methodological approaches in a mixed methods approach. Central to this is the idea that quantitative research facilitates and complements qualitative research and vice versa. One of the primary difficulties associated with the examination and measurement of quality of life factors in a city is that they are difficult to define because of their qualitative nature. Hence, in addition to the need to identify trends/progress with regard to quality of life in the city, this project recognised that the investigation of quality of life issues requires a qualitative understanding of the subject matter. Consequently, the first stage of this research project employed focus group discussions to enable the public to identify and collaboratively discuss a variety of quality of life issues that are pertinent to living in Galway. The second stage of the research utilised an extensive questionnaire survey of a large number of respondents (200) researching quality of life in their neighbourhoods and in the city as a whole to produce a large body of quantitative data for statistical analysis and comparative research. Both stages are discussed in more detail below. In addition, as citizens across every urban area reside in very varied circumstances the research sample for both stages of the project were chosen from various geographical areas, encompassing a full range of socioeconomic groups from across the city.

Focus groups, or group interview, are increasingly being adopted and developed as a powerful technique in policy-making and academic research [20]. 
Krueger [21] notes that this tool differs from other research methods in that it facilitates group interaction and a deeper insight into the reasoning behind opinions. For the purposes of this research nine focus groups were conducted to discuss the topic of quality of life in Galway. They included groups representing school children, third level students, the chamber of commerce, retired citizens, and a variety of residents' and community organisations. In particular, utilisation of the focus group methodology facilitated the inclusion of the often silent voices of youth by gaining an insight into young people's perspective of quality of life issues in Galway. A schedule of questions was formulated prior to the focus group sessions outlining the key topics for discussion including perceptions of what factors make up quality of life in Galway and opinions on current quality of life in the city. Each discussion varied in length and lasted approximately between one and two hours. The results from the nine focus group discussions are presented in Table 1 and are considered further below. Comparison of the focus group results with existing local authority indicators revealed a number of gaps with regard to quality of life indicators in Galway City.

Building on the information from the focus group research, a questionnaire survey was established to both access and assess previously unavailable data. The aim of the survey was to establish new baseline information about quality of life in Galway City. The topics contained within the questionnaire covered a wide range of quality of life issues, including perceptions of community, crime, facilities, environmental and economic aspects of life in both the respondent's neighbourhood and throughout the city of Galway. In addition to issues identified through the focus groups, topics were also derived from previous international quality of life studies such as Bristol City's Annual Quality of Life Reports (see www.bristol-city.gov.uk) and the European Urban Audit Perception Survey (see www.urbanaudit.org). Using the city's electoral register a nested random sample of 200 addresses was selected from five city wards that included a diverse range of socioeconomic classes. Depending on the respondent each questionnaire took approximately 10-20 minutes to complete. The fieldwork and analysis of the data gathered was conducted between January and March 2006. In accordance with the goals of sustainable development, the face-to-face format of the questionnaire survey and use of visual aids meant that the survey did not exclude individuals traditionally marginalised from conventional written questionnaire surveys, such as persons who are functionally illiterate. In addition to questions relating to quality of life, the final section of the questionnaire survey covered demographic and household characteristics of the sample population. The questionnaire respondents were $48.5 \%$ male and $51.5 \%$ female. This is in line with the most recent national census data which revealed that the city's population compromised of $47.1 \%$ males and $52.9 \%$ females in $2002.63 \%$ of respondents were aged 15 - 44 years and only $7 \%$ were $65+$ years of age. However, Galway has a relatively young population and these figures correlate with data from the national census which reveals that $25.9 \%$ of Galway City's population is aged 15-24 [3]. Almost $88 \%$ of questionnaire respondents had a Leaving Certificate or third level qualification. This figure directly relates to the relatively young age structure of the respondents. The 2002 national census 
shows that recent generations are better educated. The percentage of the Galway population (aged 15 or older) who completed their education with a third level qualification was $40.8 \%$ in 2002 which compares favourably with the national figure of $26 \%$ [3]. Finally, in contrast to the national census data which depicts a strong tendency towards privately owned housing $(77 \%$ of households in Ireland are owner occupied), only $50 \%$ of the questionnaire respondents resided in owner occupied housing, while $42 \%$ lived in privately rented accommodation, and $8 \%$ lived in social housing. As one of the objectives of the research is to examine variations in perceptions of quality of life across different neighbourhoods within the city, it is critical to note that the profile of the residents responding to this survey reflects, for the most part, the broader profile of the five electoral divisions chosen for this research.

Table 1: Quality of life themes identified from the focus group discussions.

\begin{tabular}{|c|c|c|}
\hline $\begin{array}{l}\text { Critical Quality of Life } \\
\text { Themes and Examples }\end{array}$ & $\begin{array}{l}\text { Examples of Qualitative } \\
\text { and Quantitative } \\
\text { Indicators } \\
\text { Qnt = Quantitative } \\
\text { Qual = Qualitative }\end{array}$ & $\begin{array}{l}\text { Status (Available = } \\
\text { pre existing data } \\
\text { available from } \\
\text { Municipal Authority/ } \\
\text { Not Available = no data } \\
\text { exists prior to } \\
\text { questionnaire results) }\end{array}$ \\
\hline $\begin{array}{l}\text { Transport } \\
\text { E.g.: issues with bus service, } \\
\text { cycling facilities in the city, } \\
\text { traffic, pedestrian crossings }\end{array}$ & $\begin{array}{l}\text { Qnt - bus route service } \\
\text { Qual - perception of cycle lanes } \\
\text { Qual - perception/accessibility of } \\
\text { bus service }\end{array}$ & $\begin{array}{l}\text { Available } \\
\text { Not Available } \\
\text { Not Available }\end{array}$ \\
\hline $\begin{array}{l}\text { Size /Compactness } \\
\text { E.g.: population size, distance to } \\
\text { walk within the city }\end{array}$ & $\begin{array}{l}\text { Qnt - population data } \\
\text { Qual - perceptions of } \\
\text { compactness of the city }\end{array}$ & $\begin{array}{l}\text { Available } \\
\text { Not Available }\end{array}$ \\
\hline $\begin{array}{l}\text { Community } \\
\text { E.g.: sense of community, } \\
\text { cohesion and integration, older } \\
\text { people/children }\end{array}$ & $\begin{array}{l}\text { Qnt - no of community groups } \\
\text { registered with local authority } \\
\text { Qual - sense of belonging in a } \\
\text { neighbourhood }\end{array}$ & $\begin{array}{l}\text { Available } \\
\text { Not Available }\end{array}$ \\
\hline $\begin{array}{l}\text { Identity } \\
\text { E.g.: character of the city, } \\
\text { buildings, traditions associated } \\
\text { with the city }\end{array}$ & $\begin{array}{l}\text { Qnt - no of traditionally based } \\
\text { businesses in the city } \\
\text { Qual - perceptions of the } \\
\text { character of a city }\end{array}$ & $\begin{array}{l}\text { Available } \\
\text { Not Available }\end{array}$ \\
\hline $\begin{array}{l}\text { Facilities } \\
\text { E.g.: availability and access of } \\
\text { facilities, facilities for older } \\
\text { people, for children }\end{array}$ & $\begin{array}{l}\text { Qnt - No of leisure and health } \\
\text { centres in the city } \\
\text { Qual - perceptions of } \\
\text { accessibility and quality of } \\
\text { facilities }\end{array}$ & $\begin{array}{l}\text { Available } \\
\text { Not Available }\end{array}$ \\
\hline $\begin{array}{l}\text { Planning and Development } \\
\text { E.g.: building development, } \\
\text { neglected plots of land }\end{array}$ & $\begin{array}{l}\text { Qnt - no of recent completions } \\
\text { Qual - perception of building } \\
\text { development }\end{array}$ & $\begin{array}{l}\text { Available } \\
\text { Not Available }\end{array}$ \\
\hline $\begin{array}{l}\text { Environment } \\
\text { E.g.: availability/accessibility of } \\
\text { green areas, litter, recycling }\end{array}$ & $\begin{array}{l}\text { Qnt }- \text { no of parks } \\
\text { Qual - usage of parks, quality of } \\
\text { green areas }\end{array}$ & $\begin{array}{l}\text { Available } \\
\text { Not Available }\end{array}$ \\
\hline $\begin{array}{l}\text { Economic } \\
\text { E.g.: cost of living, employment } \\
\text { opportunities }\end{array}$ & $\begin{array}{l}\text { Qnt - unemployment figures } \\
\text { Qnt - national GDP } \\
\text { Qual - perception of cost of } \\
\text { living within the city }\end{array}$ & $\begin{array}{l}\text { Available } \\
\text { Available } \\
\text { Not Available }\end{array}$ \\
\hline $\begin{array}{l}\text { Social } \\
\text { E.g.: homelessness, non-national } \\
\text { integration }\end{array}$ & $\begin{array}{l}\text { Qnt - figures for residents in } \\
\text { homeless shelters } \\
\text { Qual - perceptions of integration }\end{array}$ & $\begin{array}{l}\text { Available } \\
\text { Not Available }\end{array}$ \\
\hline
\end{tabular}




\section{Results}

The results of the focus group discussions (summarised in Table 1) reveal a range of quality of life themes and indicators as identified by the public. Nine key themes emerged from the focus groups: transport, size of the city, community, identity, facilities, planning and development, environment, economic, and social. These themes were formulated following the transcription and analysis of the focus group discussions by citizens involved in the focus group sessions. These classifications are flexible; they are not regarded as definitive and some factors/indicators could be included in more than one of the categories identified. The focus group discussions revolved around the topic of what determined quality of life in Galway and the respondents identified both positive and negative features of each of the themes listed in Table 1. 'Environment', for example, was one of the nine critical themes which participants identified as influencing quality of life in the city. Discussions relating to this theme encompassed dissatisfaction with litter and the poor appearance of some city streetscapes. Within the same theme obvious satisfaction with recycling facilities operating within the city was strongly expressed. It is also interesting to note that within the 'Environment' theme, availability of and accessibility to green areas was a recurring issue which surfaced in most of the focus group discussions. While the municipal authority has data outlining the amount and size of green areas available within the city boundary, participants expressed a variety of opinions about usage of these green areas and access to them. These community-derived themes were investigated and tested further in the second stage of the research, the questionnaire survey.

An overview of questionnaire survey findings relating to a select number of factors examined is presented here. The factors reported on include overall satisfaction with neighbourhoods, perceptions of belonging, and crime in respondents' local areas. For the purposes of this overview, results for the five electoral districts are presented collectively. The vast majority (91.5\%) of all respondents were 'fairly satisfied' or 'very satisfied' with their neighbourhood as a place to live. Indeed, only $13 \%$ of respondents felt that their neighbourhood had got worse over the past two years, while $15 \%$ felt that it had improved, and $46.5 \%$ felt that it had not changed. $(25.5 \%$ had lived in their neighbourhoods less than two years). Overall, $67 \%$ of respondents felt that they belonged in their neighbourhoods, while $25.5 \%$ felt they did not and $7.5 \%$ really did not know. Of those respondents that felt they did not belong in their neighbourhoods $51 \%$ resided in privately rented accommodation and $25.5 \%$ had lived in the neighbourhood for less than two years. In total, $82.8 \%$ of all respondents 'strongly agree' or 'somewhat agree' with the statement 'I trust most of the people living in my local area'. With regard to crime and safety $17 \%$ of respondents felt that their neighbourhoods were 'very safe outdoors after dark', while $52.5 \%$ felt they were 'fairly safe', $18 \%$ felt that they were 'neither safe nor unsafe', $10 \%$ felt they were 'fairly unsafe' and $2 \%$ felt they were 'very unsafe'. On the topic of crime and safety in Galway City as a whole, 79.3\% 'strongly agreed' or 'somewhat agreed' with the statement 'I feel safe in the city'. 
Regarding other quality of life issues in the city, only $26.3 \%$ of respondents 'strongly' or 'somewhat' agreed with the statement that 'it is easy to find good housing at a reasonable cost' while $65.6 \%$ 'strongly' or 'somewhat' disagreed with this statement. With regard to employment $40.4 \%$ of respondents 'strongly' or 'somewhat' agreed with the statement 'it is easy to find a job in Galway City' while $35.4 \%$ 'strongly' or 'somewhat' disagreed with this statement. With regard to environmental factors, $72.8 \%$ of respondents 'strongly' or 'somewhat' disagreed with the statement that 'air pollution is a big problem in Galway' and $59.6 \%$ concurred with the statement that Galway 'is a clean city'. On the issue of integration $56.9 \%$ of respondents felt that 'non-nationals who live in Galway are well integrated'. In answer to a later question $27.9 \%$ felt that there was either 'a lot of tension' or 'some tension' between different racial and ethnic groups in the city. Overall, $70 \%$ of all respondents 'strongly agreed' with the statement 'I am satisfied living in Galway' and a further $27.5 \%$ 'somewhat agreed' with this statement.

In addition to questions relating to quality of life issues at the local neighbourhood level and at the wider city level, respondents were asked to rank (on a scale of 1-10 where 1 indicates dissatisfaction and 10 indicates very satisfied) their satisfaction with personal quality of life factors. The results (presented in Table 2) indicate a high level of personal satisfaction on most counts.

Table 2: $\quad$ Satisfaction with personal quality of life factors.

\begin{tabular}{|l|r|}
\hline Satisfied (i.e. ranked the factor 8, 9 or 10 ) with... & $\%$ \\
\hline Current job & 53 \\
\hline Education & 51 \\
\hline Accommodation & 68 \\
\hline Social life & 62 \\
\hline Health & 75 \\
\hline Family life & 73 \\
\hline Current standard of living & 73 \\
\hline
\end{tabular}

\section{Conclusion}

The focus group discussions identified a number of themes and indicators the participants considered significant to quality of life in the city of Galway. When these are considered in light of existing data and indicators previously available from the municipal authority, it is interesting to note the discrepancy between what Moller terms as 'objective' and 'subjective' indicators (objective indicators are tangible facts that can be readily observed and subjective indicators are personal judgements of objective conditions [18]) and in particular the dearth of data relating to subjective indicators in Galway. It is evident from the results, presented in Table 1, that additional indicators are required to represent a holistic view of quality of life in the city of Galway. These additional indicators were identified and tested through the use of the questionnaire survey. In addition to establishing new baseline data, drawing on the research of Cutter [15], the survey examined perceptions of personal quality of life. The results suggest that, 
by and large, high levels of satisfaction exist with regard to many elements of quality of life in Galway City. The preliminary results presented in this paper relate primarily to the city as a whole and do not differentiate between the various city neighbourhoods that were surveyed. Further analysis and statistical breakdown of results by electoral ward will address this matter. In addition, research studies concentrating on quality of life in urban areas present a clear opportunity to examine the interface between subjective and objective relationships [18] and this aspect of the research will be developed with further analysis.

Central to this project is the engagement of Galway City Council in dialogue with citizens and communities in order to gather relevant information and shape sustainable development practices. The sustainable development discourse places heavy emphasis on the need to develop more democratic mechanisms for decision making. In this sense, regardless of the final tangible outputs - the final set of quality of life indicators - the actual process of collating the data is an end in itself. Community-derived indicators allow individual citizens and communities to express and measure the most important determinants of quality of life for them. These indicators may be monitored in Galway City on an ongoing basis into the future. The development and deployment of communityderived quality of life indicators as outlined in this paper represent a significant step towards the goal of sustainability in Galway City.

\section{References}

[1] Portney, K.E. Taking Sustainable Cities Seriously MIT Press: Cambridge, MA, 2003.

[2] Bell, S. and Morse, S. Sustainability Indicators, Earthscan: London, 1999.

[3] Central Statistics Office 2002 Census of Population: Preliminary Report. Central Statistics Office: Dublin, 2002.

[4] LASALA (Local Authorities Self Assessment of Local Agenda 21) Accelerating Local Sustainability - Evaluating European Local Agenda 21 Processes, ICLEI: Freiburg, 2001.

[5] EPA (Environmental Protection Agency) Environment in Focus 2002: Key Environmental Indicators for Ireland Environmental Protection Agency: Wexford, 2002.

[6] Mullally, G. Starting Late: building institutional capacity on the reform of sub-national governance Sustainable Communities in Europe ed. Lafferty, W. Earthscan: London, 2001.

[7] UNCED (United Nations Conference on Environment and Development) Agenda 21 - Action Plan for the Next Century, UNCED, Rio de Janeiro, 1992.

[8] Gahin, R., Veleva, V. and Hart, M. Do Indicators Help Create Sustainable Communities, Local Environment, 8(6), 661-666, 2003.

[9] Wheeler, S. Planning for Sustainability: Creating Livable, Equitable, and Ecological Communities Routledge: UK, 2004. 
[10] Rydin, Y., Holman, N and Wolff, E. Local Sustainability Indicators, Local Environment 8(6) pp. 581-590, 2003.

[11] Hoernig, H. and Seasons, M. Understanding Indicators Community Indicators Measuring Systems ed. Phillips, R. Ashgate: UK, pp. 3-32, 2005.

[12] McAlpine, P. and Birnie, P. Is there a Correct Way of Establishing Sustainability Indicators? The Case of Sustainability Indicator Development on the Island of Guernsey, Local Environment, 10(3) pp.243-257, 2005.

[13] Sommer, F. Monitoring and Evaluating Outcomes of Community Involvement - the LITMUS Experience, Local Environment 5(2) pp. 4834912000.

[14] Journel, C., Duchene, F., Coanus, T., and Martinais, E. Devising Local sustainable Development Indicators Local Environment 8(6) pp. 615-626 2003.

[15] Cutter, S.L. Rating Places: a geographers view on quality of life, Association of American Geographical Research Publishers: USA, 1985.

[16] Kline, E. Indicators for Sustainable Development in Urban Areas How green is the city? ed. Devuyst, D., Columbia: USA, pp. 275-298, 2001.

[17] Devuyst, D. How green is the city? Columbia: USA, 2001.

[18] Moller, V. Monitoring quality of life in cities: the Durban case Development Southern Africa 18(2) pp 217-222, 2001.

[19] Hobson, K. Thinking habits into action: the role of knowledge and process in questioning household consumption practices Local Environment, 8(1) pp.95-112, 2003.

[20] Davies, A.R. Where Do We Go From Here? Environmental focus groups and planning policy formation, Local Environment, 4(3) pp.295-315, 1999.

[21] Krueger, R.A. Focus Groups: A Practical Guide for Applied Research. Sage: USA 1994. 